\title{
Negative extrathoracic pressure ventilation for phrenic nerve palsy after paediatric cardiac
} surgery

\author{
J Raine, M P Samuels, Q Mok, E A Shinebourne, D P Southall
}

Department of Paediatrics, National Heart and Lung Institute, Royal Brompton National Heart and Lung Hospital, London J Raine

M P Samuels

Q Mok

E A Shinebourne D P Southall

Correspondence to Dr D P Southall, Department of Paediatrics, National Heart and Lung Institute, Royal Brompton National Heart and Lung Hospital, Sydney Street, London SW3 6NP.

Accepted for publication 25 July 1991

\begin{abstract}
Objective-To investigate the feasibility of negative extrathoracic pressure ventilation as a respiratory support following phrenic nerve palsy after cardiac surgery.

Design-An uncontrolled pilot study.

Patients-14 patients aged one week to 30 months (median $5 \cdot 3$ months) with phrenic nerve palsy diagnosed by phrenic nerve conduction tests and diaphragmatic electromyograms. Four had bilateral and 10 unilateral palsy. Before treatment all required oxygen and 10 were receiving positive pressure ventilation. One of the patients with bilateral and four of the patients with unilateral palsies had undergone a plication before negative pressure ventilation was started.
\end{abstract}

Intervention-Treatment was started 6-65 days (median 23) after operation with a newly designed system which included a Perspex chamber, which gave easy access to the child, and an elastic latex neck seal. Continuous negative pressure was used in conjunction with intermittent positive pressure ventilation while continuous or intermittent negative pressure ventilation was used in extubated infants.

Results-All four patients with bilateral palsy survived with long-term intermittent negative pressure ventilation and did not require further surgery. Of the 10 with unilateral lesions, seven required no further surgery, two underwent plication, and one had a re-plication. Three patients with unilateral palsy died of non-respiratory causes. The duration of positive pressure ventilation after starting negative pressure ranged from 0 to 23 days (median 6). Treatment with negative pressure lasted for 3-241 days (median 32) and was predominantly administered of the intensive care unit, including at home.

Conclusions-Negative pressure ventilation may be an alternative to positive airway pressure ventilation in the management of phrenic nerve palsy. A multicentre randomised controlled trial is now required to assess further the role of negative pressure ventilation in phrenic nerve palsy.
Phrenic nerve palsy is a complication of surgery for congenital heart disease ${ }^{1}$ that can cause respiratory failure and necessitate prolonged ventilation via an endotracheal tube or a tracheostomy. ${ }^{2}$ These techniques contribute to the development of infections of the lower respiratory tract, often in the atelectatic lung adjacent to the paralysed diaphragm, thus further prolonging the need for respiratory support. The younger the child the more marked the respiratory compromise. This is due to the infant's greater reliance on the diaphragm for breathing in the presence of a relatively horizontal rib cage, a compliant chest wall, and a recumbent posture. ${ }^{3-5}$ Treatment of phrenic nerve palsy is initially conservative but if the patient cannot be weaned from positive airway pressure ventilation or has a persistent oxygen requirement, diaphragmatic plication is usually performed. ${ }^{1}$ However, this surgical procedure does not always ameliorate the respiratory failure, which may require treatment for weeks or months even in patients in whom the nerve injury is temporary.

We report our findings in 14 patients with phrenic nerve palsy, some of whom had undergone diaphragmatic plication. Negative extrathoracic pressure ventilation was used with the aim of providing respiratory support without the need for a plication or replication, long-term endotracheal intubation, or tracheostomy.

\section{Patients and methods}

PATIENTS

The table shows the clinical details of the 14 patients with phrenic nerve palsy who were treated with negative extrathoracic pressure ventilation between July 1987 and March 1990. In all patients the diagnosis of phrenic nerve palsy was based on the observation of paradoxical abdominal movement during spontaneous respiration, fluoroscopic and/or ultrasonic findings of an elevated raised hemi-diaphragm with paradoxical movement on spontaneous breathing, and impaired phrenic nerve latencies and diaphragmatic electromyograms. Before treatment with negative pressure, all 14 patients were receiving oxygen and 10 were receiving intermittent positive pressure ventilation. The four infants who were breathing spontaneously had been weaned off positive airway pressure respiratory support 1-7 days (median 1) before negative pressure treatment was started. 
Table 1 Patient details before and after the start of ventilation by negative extrathoracic pressure (VNEP)

\begin{tabular}{|c|c|c|c|c|c|c|c|c|c|}
\hline $\begin{array}{l}\text { Patient } \\
\text { No }\end{array}$ & Diagnosis & Surgery & $\begin{array}{l}\text { Site of } \\
P N P\end{array}$ & Plication & $\begin{array}{l}\text { Duration of } \\
I P P V \text { before } \\
V N E P \text { (days) }\end{array}$ & $\begin{array}{l}\text { Duration of } \\
\text { IPPV after } \\
V N E P \text { (days) }\end{array}$ & $\begin{array}{l}\text { Duration of } \\
V N E P \text { (days) }\end{array}$ & $\begin{array}{l}\text { Plication/ } \\
\text { replication } \\
\text { after VNEP }\end{array}$ & Survival \\
\hline $\begin{array}{l}1 \\
2 \\
3 \\
4 \\
5 \\
6 \\
7 \\
8\end{array}$ & $\begin{array}{l}\text { TGA, VSD, PS } \\
\text { TGA } \\
\text { TGA, VSD, PS, PDA } \\
\text { TGA, PS } \\
\text { TOF } \\
\text { TGA } \\
\text { TOF } \\
\text { TGA, VSD, ASD, } \\
\text { previous PA banding, } \\
\text { ligation of PDA and } \\
\text { repair of coarctation }\end{array}$ & $\begin{array}{l}\text { Right B-T shunt } \\
\text { Mustard's procedure } \\
\text { Left B-T shunt } \\
\text { Right B-T shunt } \\
\text { Full repair } \\
\text { Senning's procedure } \\
\text { Full repair } \\
\text { Arterial switch } \\
\text { Closure of VSD }\end{array}$ & $\begin{array}{l}\text { Right } \\
\text { Bilateral } \\
\text { Left } \\
\text { Right } \\
\text { Left } \\
\text { Bilateral } \\
\text { Left } \\
\text { Left }\end{array}$ & $\begin{array}{l}\text { Yes } \\
\text { No } \\
\text { Yes } \\
\text { Yes } \\
\text { No } \\
\text { Yes } \\
\text { Yes } \\
\text { No }\end{array}$ & $\begin{array}{r}22 \\
24 \\
7 \\
25 \\
5 \\
41 \\
20 \\
23\end{array}$ & $\begin{array}{r}3 \\
16 \\
0 \\
23 \\
8 \\
4 \\
10 \\
7\end{array}$ & $\begin{array}{r}9 \\
97 \\
77 \\
13 \\
3 \\
233 \\
6 \\
61\end{array}$ & $\begin{array}{l}\text { Yes } \\
\text { No } \\
\text { No } \\
\text { No } \\
\text { Yes } \\
\text { No } \\
\text { No } \\
\text { No }\end{array}$ & $\begin{array}{l}\text { Dead } \\
\text { Alive } \\
\text { Alive } \\
\text { Dead } \\
\text { Alive } \\
\text { Alive } \\
\text { Dead } \\
\text { Alive }\end{array}$ \\
\hline $\begin{array}{r}9 \\
10 \\
11 \\
12\end{array}$ & $\begin{array}{l}\text { TGA } \\
\text { TGA, VSD } \\
\text { TGA, VSD, PDA } \\
\text { Anomalous left } \\
\text { coronary artery }\end{array}$ & $\begin{array}{l}\text { Arterial switch } \\
\text { Mustard's procedure } \\
\text { Arterial switch } \\
\text { Full repair }\end{array}$ & $\begin{array}{l}\text { Left } \\
\text { Left } \\
\text { Left } \\
\text { Bilateral }\end{array}$ & $\begin{array}{l}\text { No } \\
\text { No } \\
\text { No } \\
\text { No }\end{array}$ & $\begin{array}{l}12 \\
57 \\
15 \\
36\end{array}$ & $\begin{array}{l}0 \\
0 \\
0 \\
7\end{array}$ & $\begin{array}{r}5 \\
11 \\
24 \\
241\end{array}$ & $\begin{array}{l}\text { No } \\
\text { No } \\
\text { No } \\
\text { No }\end{array}$ & $\begin{array}{l}\text { Alive } \\
\text { Alive } \\
\text { Alive } \\
\text { Alive }\end{array}$ \\
\hline $\begin{array}{l}13 \\
14\end{array}$ & $\begin{array}{l}\text { TGA } \\
\text { TGA, VSD, Mustard's } \\
\text { procedure at } 1 \text { year }\end{array}$ & $\begin{array}{l}\text { Arterial switch } \\
\text { Relief of pulmonary } \\
\text { venous obstruction }\end{array}$ & $\begin{array}{l}\text { Bilateral } \\
\text { Right }\end{array}$ & $\begin{array}{l}\text { No } \\
\text { No }\end{array}$ & $\begin{array}{l}34 \\
18\end{array}$ & $\begin{array}{r}10 \\
5\end{array}$ & $\begin{array}{r}165 \\
40\end{array}$ & $\begin{array}{l}\text { No } \\
\text { Yes }\end{array}$ & $\begin{array}{l}\text { Alive } \\
\text { Alive }\end{array}$ \\
\hline
\end{tabular}

ASD, atrial septal defect; B-T, Blalock-Taussig; PDA, patent ductus arteriosus; PNP, phrenic nerve palsy; PA, pulmonary artery; PS, pulmonary stenosis; TOF, tetralogy of Fallot; TGA, transposition of great arteries; VSD, ventricular septal defect; IPPV, intermittent positive airway pressure ventilation.

The indication for negative extrathoracic pressure ventilation was difficulty in weaning from positive pressure ventilation or, in those breathing spontaneously, a persistent or increasing oxygen requirement and respiratory distress. The timing of the start of treatment was partly dependent on the availability of equipment. Ages at the start of treatment ranged from one week to 30 months (median 5.3 months) and weight from $2.3 \mathrm{~kg}$ to $10 \mathrm{~kg}$ (median $5.3 \mathrm{~kg}$ ). Negative pressure treatment started 6-65 days (median 23) after cardiac surgery.

\section{METHODS}

The system for applying negative extrathoracic pressure ventilation (Horner and Wells, DHB Tools) has been described in detail elsewhere. ${ }^{6}$ In brief, it consists of a Perspex chamber that encloses the patient from below the neck. The chamber is made airtight by a latex neck seal that is placed over a polo-necked stockinet vest on the infant. Routine access was via two portholes on each side of the chamber. Foam gaskets on the inside of these portholes formed a seal round the arms enabling the negative pressure to be maintained while routine care was being administered. Emergency access could be gained by undoing two quick-release catches at the side of the chamber, thus allowing the lid of the chamber to swing upwards, to give easy and rapid access to the infant.

In intubated patients receiving positive pressure ventilation, continuous negative extrathoracic pressure was applied at pressures of -6 to $-8 \mathrm{~cm}$ water. At the same time, the peak inspiratory pressure was reduced by the magnitude of the negative pressure used and the end-expiratory pressure was reduced as close as possible to zero. For example, an infant receiving peak inspiratory/end expiratory pressures of $+26 / 4 \mathrm{~cm} \mathrm{H}_{2} \mathrm{O}$ would change to $+18 / 0 \mathrm{~cm} \mathrm{H}_{2} \mathrm{O}$ immediately before a continuous negative pressure of $-8 \mathrm{~cm} \mathrm{H}_{2} \mathrm{O}$ was applied. If continuous negative pressure had to be stopped temporarily, the reverse pressure changes were made.
Immediately after extubation, intermittent negative pressure ventilation was started. It was also used to avoid reintubation in patients who were breathing spontaneously and had deteriorated despite continuous negative pressure. During intermittent negative pressure, peak pressures of -30 to $-40 \mathrm{~cm} \mathrm{H}_{2} \mathrm{O}$ were used with end expiratory pressures of -6 to $-8 \mathrm{~cm} \mathrm{H}_{2} \mathrm{O}$. Extubated patients were gradually weaned from intermittent to continuous negative extrathoracic pressure. As the patient's condition improved the chamber was opened every 4-12 hours for feeding and parental contact and the patient spent increasingly longer times out of the chamber.

Parents were encouraged to take part in nursing their child both in and out of the chamber. When treatment was to continue at home parents were trained to use the negative pressure respiratory support system and were provided with a transcutaneous oxygen monitor (Kontron 821S, Watford) specially modified for home use. ${ }^{7}$

Phrenic nerve testing is a useful bedside technique for the diagnosis of nerve injury and resultant diaphragmatic palsy. The details of the technique have been described elsewhere. ${ }^{8}$ It involves percutaneous stimulation of the phrenic nerves in the neck and recordings of the diaphragmatic compound muscle action potential as electromyograms from surface electrodes. The diagnosis of phrenic nerve injury is based on the assessment of delayed phrenic nerve latency (conduction time) or an absent diaphragmatic electromyogram despite repeated phrenic nerve stimulation.

Diaphragmatic plication was performed by standard techniques. ${ }^{19}$

\section{Results}

The table outlines the results of treatment with negative pressure. All four children with bilateral phrenic nerve palsy survived after long-term intermittent negative pressure ventilation and did not receive further surgery. After the start of negative pressure in the 10 
patients with unilateral phrenic nerve palsies, seven recovered without further surgery, two had plication, and one a re-plication. One of the three patients who had a plication could not be extubated and underwent a further period of treatment with negative pressure after this operation. Plication was performed in all three cases because respiratory failure continued despite respiratory support with negative pressure.

Three of the patients with unilateral palsy died: one from candidal septicaemia, one intraoperatively during a pulmonary artery banding, and one after a cardiac arrhythmia which led to a cardiac arrest.

The length of positive pressure ventilation after the start of negative extrathoracic pressure ventilation ranged from 0 to 23 days (median 6). Treatment with negative pressure lasted from three to 241 days (median 32). The patients required intensive care for 14-99 days (median 38) and treatment in hospital for 26186 days (median 75 ). Three patients with bilateral phrenic nerve palsy continued treatment at home for 93,108 , and 113 days.

There were no statistically significant differences in the total duration of respiratory support with either positive or negative pressure or between the five patients who had undergone a plication before negative pressure treatment and those who had not (MannWhitney U test).

Two of the 14 patients temporarily developed sore necks as a result of intermittent negative pressure treatment but in neither case did this necessitate discontinuation of the treatment. There were no other complications.

Phrenic nerve conduction studies were repeated at intervals according to the patient's respiratory state and the frequency of their outpatient attendances. These studies were useful in assisting in decisions about the duration of treatment and the prognosis. Nine of the 14 patients recovered normal phrenic nerve latency and diaphragmatic electromyograms at 1.5 to 25 months (median 15) after operation. The three patients who died showed no recovery in phrenic nerve conduction by the time of death, one patient showed no recovery 10 months postoperatively, and one was lost to follow up. Most patients showed clinical evidence of improvement before electrophysiological evidence of recovery.

At follow up, 2-22 months (median 9.5) after the end of the negative pressure treatment, the 11 surviving patients showed clinically normal respiratory function.

\section{Discussion}

Retrospective studies have reported phrenic nerve palsy in $1-2 \%$ of patients after surgery for congenital heart disease. ${ }^{12}$ In a prospective study in which we used percutaneous stimulation of the nerve to confirm phrenic nerve injury, this complication was found in $10 \%$ of cases. ${ }^{8}$ The probable reason for the underdiagnosis of phrenic nerve palsy is that many children with abnormal electrophysiological studies do not have apparent clinical manifesta- tions. In addition, the non-specific nature of clinical signs, such as a raised hemi-diaphragm on the chest radiograph, may result in the diagnosis not being considered. The use of phrenic nerve testing and the analysis of the terminal latencies and diaphragmatic electromyograms were helpful in diagnosis and in assessing the degree of recovery.

A mortality of between $10 \%$ (three of 32 cases) ${ }^{2}$ and $36 \%$ (four of 11 cases) $)^{9}$ has been reported in children with congenital heart disease and unilateral palsies. There are no data on mortality in bilateral palsies ${ }^{10}$ but they would probably show an even higher incidence.

The use of negative extrathoracic pressure ventilation as a form of respiratory support dates back to the last century. ${ }^{11}$ A previous case report describes the use of this treatment in an infant with diaphragmatic paralysis after a birth injury. ${ }^{12}$ Both positive airway pressure ventilation and continuous negative extrathoracic pressure can help to stabilise the paralysed diaphragm and thereby prevent it from encroaching on tidal volume by paradoxical motion. However, negative pressure has two advantages over positive pressure respiratory support given through an endotracheal airway. Firstly, negative pressure support is non-invasive and may obviate the need for endotracheal intubation or tracheostomy; both are techniques that increase the risk of introducing pathogens into the lung. Moreover, because diaphragmatic paralysis may impair the ability to clear secretions, the risk of infection is particularly high in intubated patients with phrenic nerve palsy. Secondly, negative pressure has important theoretical haemodynamic advantages. Positive airway pressure ventilation may decrease venous return to the right side of the heart, increase pulmonary vascular resistance, and reduce pulmonary blood flow. ${ }^{13} \mathrm{~A}$ reduction in pulmonary blood flow may be particularly deleterious after cardiac surgery, especially when pulmonary blood flow is already compromised. The use of positive pressure ventilation in conjunction with continuous negative pressure, as outlined above, can lead to a fall in mean airway and mean intrathoracic pressures. The fall in mean intrathoracic pressure would in turn be expected to improve systemic venous return and pulmonary blood flow. However, in lesions with a left to right shunt such as a ventricular septal defect, increased pulmonary blood flow may be disadvantageous in that it might precipitate or exacerbate pulmonary oedema. This potential complication was not identified in any of our patients.

Nasal continuous positive airway pressure is less invasive than endotracheal intubation and could be considered an alternative to negative pressure treatment. However, ventilation with such a system is less practicable because the proportion of positive pressure reaching the lungs is variable and is much reduced whenever the patient's mouth opens.

The use of negative extrathoracic pressure ventilation in infants and children largely ceased in the 1970s. This was the result of advances in the application of positive airway 
pressure ventilation and the technical problems associated with the use of negative pressure. The latter included difficulties in obtaining an adequate neck seal and in gaining access to the patient. Having redesigned the negative pressure chamber to overcome these difficulties we have re-introduced it into paediatric practice. ${ }^{6}$

In this preliminary and uncontrolled study there were no strict criteria for the initiation of negative pressure treatment. Treatment was started when the cardiologist thought that the child's respiratory course was failing to improve despite standard treatment.

Of the six patients with unilateral lesions undergoing positive pressure ventilation after the initiation of negative pressure, two received a plication and one a re-plication. Two of these three plications took place when only the continuous mode of negative pressure was available; that is, before the development of intermittent negative pressure ventilation. One plication was, however, required despite the use of intermittent negative pressure ventilation. The four spontaneously breathing infants with unilateral lesions and the four infants with bilateral lesions all progressed without requiring further surgery. Thus negative pressure may have led to the avoidance of plication or replication in 11 of these 14 patients.

The four patients with bilateral lesions required negative pressure treatment for a prolonged period of three to nine months. Access to the infant nursed in a negative pressure chamber is more limited than that in an infant undergoing positive pressure respiratory support. Stimulation and play and consequently development could therefore be hampered in infants requiring long-term treatment. However, as lung function improved, the patient was able to be taken out of the negative pressure chamber for progressively longer periods to be cuddled, played with, and stimulated. These difficulties with access have to be balanced against the advantages of negative pressure. These include the avoidance of long-term intubation and its associated problems with infection, and the greater feasibility of using negative pressure support outside the intensive care unit and at home.

Further improvements to the negative pressure system have recently been achieved, ${ }^{14}$ including for example the development of a port in the base of the chamber for the insertion of $x$ ray films allowing a radiograph to be taken without disturbance to the negative pressure.

Our results suggest that negative extrathoracic pressure ventilation is an effective and practicable treatment and may be an important alternative to long-term positive airway pressure ventilation in infants and children with unilateral or bilateral phrenic nerve palsy after surgery for congenital heart disease. A randomised controlled trial is required to evaluate negative pressure ventilatory support in the treatment of phrenic nerve palsy and to assess its possible role as an alternative to positive airway pressure ventilation and to diaphragmatic plication.

JR is funded by the clinical research committee of the Royal Brompton and National Heart and Lung Hospital (RBNHLH), MPS is funded by the Little Ones charity, and DPS by the Foundation for the Study of Infant Death and the RBNHLH. This project was funded by the Priory Foundation and the Dunhill and New Moorgate Trusts.

1 Langer JC, Filler RM, Coles J, Edmonds JF. Plication of the diaphragm for infants and young children with phrenic nerve palsy. $J$ Pediatr Surg 1988;23:749-51.

2 Mickell JJ, Oh KS, Siewers RD, Galvis AG, Fricker FJ, Mathews RA. Clinical implications of postoperative unilateral phrenic nerve paralysis. $J$ Thorac Cardiovasc Surg 1978;76:297-303.

3 Robotham JL. A physiological approach to hemidiaphragm paralysis. Crit Care Med 1979;7:563-6.

4 Muller NL, Bryan AC. Chest wall mechanics and respiratory muscles in infants. Pediatr Clin North Am 1979;26: tory musci.

5 Bryan AC, Wohl MEB. Respiratory mechanics in children. In: Fishman AP, Macklem PT, Mead J, eds. Handbook of physiology. Section 3: The Respiratory System. Bethesda, Maryland: American Physiological Society, 1986:vol 3, part 1:179-91.

6 Samuels MP, Southall DP. Negative extrathoracic pressure in treatment of respiratory failure in infants and young children. BMJ 1989;299:1253-7.

7 Poets CF, Samuels MP, Noyes JP, Jones KA, Southall DP. Home monitoring of transcutaneous oxygen tension in the early detection of hypoxaemia in infants and young children. Arch Dis Child 1991;66:676-82.

8 Mok Q, Ross-Russell R, Mulvey D, Green M, Shinebourne EA. Phrenic nerve injury in infants and children undergoing cardiac surgery. Br Heart J 1991;65:287-92.

9 Stone KS, Brown JW, Canal DF, King H. Long term fate of the diaphragm surgically plicated during infancy and the diaphragm surgically plicated during
childhood. Ann Thorac Surg 1987;44:62-5.

10 Stewart S, Alexson C, Manning J. Bilateral phrenic nerve paralysis after the Mustard procedure: experience with four cases and recommendations for management. $J$ Thorac Cardiovasc Surg 1986;92:138-41.

11 Woollam CHM. The development of apparatus for intermittent negative pressure respiration (1). 1832-1918. Anaesthesia 1976;31:537-47.

12 Weisman L, Woodall J, Merenstein G. Constant negative pressure in the treatment of diaphragmatic paralysis
secondary to birth injury. Birth Defects 1976;12:297-302.

13 Tyler DC. Positive end-expiratory pressure: a review. Crit Care Med 1983;11:300-8.

14 Raine J, Wright TAM, Samuels MP, Southall DP, Modi N, Harvey $S$, et al. The use of continuous extrathoracic pressure in neonatal respiratory failure. In: Lafeber HN, ed. Fetal and neonatal physiological measurements. London: Excerpta Medica, 1991:265-70. 